\title{
Humoral immunity after Pfizer/BioNTech BNT162b2 vaccine in healthcare workers of ASL Roma 2 (Italy)
}

\author{
Eliana Giberna, ${ }^{1}$ Tiziana Guastafierro, ${ }^{2}$ Natalia Ciaffi, ${ }^{1}$ Elena Nebuloso, ${ }^{1}$ Stefania Piccoli, ${ }^{1}$ Mattia Serao, ${ }^{3}$ \\ Giuseppina Gioffrè, ${ }^{3}$ Stefania Campitelli, ${ }^{4}$ Maria Grazia Colace, ${ }^{2}$ Maria Carmela Cava, ${ }^{1}$ Maria De Cristofaro ${ }^{1}$ \\ ${ }^{1}$ Unit of Microbiology and Virology, ${ }^{2}$ Unit of Clinical Pathology and Biochemistry, ${ }^{3}$ Unit of Pneumology, ${ }^{4}$ Unit of \\ Coordination of Vaccinal Activities, Sandro Pertini Hospital Asl Roma 2, Rome, Italy
}

\begin{abstract}
Summary
The Unit (COU) of Microbiology and Virology of Sandro Pertini Hospital began monitoring the immune response on a cohort of healthcare operators who received the Pfizer/BioNTech BNT162b2 vaccine. Three different tests for the detection of antibodies against SARS-CoV-2 were used showing $100 \%$ of seroconversion after 28 days from the first dose.
\end{abstract}

\section{Introduction}

Thanks to the unprecedented speed of scientific research, it was possible to develop new vaccines against SARS-CoV-2

Correspondence: Eliana Giberna, Via Pietro Ravanas 235, Bari, Italy. Tel.: +39.392.9147790.

E-mial: eliana.giberna@aslroma2.it

Key words: vaccine, Sars-CoV-2, COVID-19, coronavirus, humoral immunity.

Contributions: EG, TG, MGC, NC, MCC and MDC conceived of the idea. EN and SP carried out the experiments. EG, MDC, TG organized blood draw timing conceived and planned the experiments, drafted the manuscript and designed the figures. EG wrote the manuscript with support from MDC and TG. MS and GG, contributed to supervised the work. SC manage the preparation and administration of the vaccine. All authors discussed the results and contributed to the final manuscript.

Conflict of interest: The authors declare no potential conflict of interest.

Funding: None.

Received for publication: 19 February 2021.

Revision received: 23 April 2021.

Accepted for publication: 23 April 2021.

${ }^{\circ}$ Copyright: the Author(s), 2021

Licensee PAGEPress, Italy

Microbiologia Medica 2021; 36:9695

doi:10.4081/mm.2021.9695

This article is distributed under the terms of the Creative Commons Attribution Noncommercial License (by-nc 4.0) which permits any noncommercial use, distribution, and reproduction in any medium, provided the original author(s) and source are credited. immediately available on the market, that has given us a very efficient weapon to face the pandemic. The Pfizer-BioNTech vaccine is an mRNA vaccine (1) that supplies the cells with instructions to build the virus protein $\mathrm{S}$, that mediates entry into host cells $(2,3)$, determining the production of neutralizing antibodies capable of recognising virus and block cells infection. From December 2020, ASL Roma 2 started administering the first doses of Pfizer/BioNTech BNT162b2 vaccine to healthcare workers. The Unit of Microbiology and Virology began monitoring the immune response on this cohort of operators.

\section{Type of the study}

The present study aimed at specifically evaluating the presence of anti-SARS-CoV-2 antibodies directed against the Receptor Binding Domain (RBD) of protein S which binds cellular receptor ACE2 (4-7). Only subjects who tested negative to an antigenic (SD Biosensor) or molecular (Roche $\AA$ Diagnostics and Seegene) swab in the two weeks prior to the vaccine administration were enrolled in the study.

Serological SARS-CoV-2 assay was performed on samples taken at predetermined times:

- t0: from 0 to 11 days from the first dose of the vaccine

- $\mathrm{t} 1$ : on the 12 th day after the first dose of the vaccine

- t2: on the 21st day after the first dose of the vaccine

- t3: 7-9 days after the second dose of the vaccine

Analysis was initially carried out on 102 healthy workers (83F, 20M; average age 54.6 years). All subjects received both doses of the vaccine, except one who contracted the virus after the first dose (t2) and was excluded from the subsequent analysis.

Three automated immunoassays were used: OrthoClinical DiagnosticsVITROS ${ }^{\circledR}$ Anti-SARS-CoV-2 Total, on VITROS ${ }^{\circledR}$ 3600 platform (S1 protein-based) in CLIA; Roche Elecsys ${ }^{\circledR}$ AntiSARS-CoV-2: Roche cobas $^{\mathrm{TM}}$ e411 analyzer (N protein-based, IgA, IgM or IgG antibodies); Roche Elecsys ${ }^{\circledR}$ Anti-SARS-CoV-2 $\mathrm{S}$ on Roche cobas ${ }^{\mathrm{TM}}$ e411 analyzer (S protein-based, IgA, IgM or IgG antibodies).

As a first screening, we used the Ortho Clinical Diagnostics kit, in order to measure all antibody isoforms (IgA, IgM and $\operatorname{IgG}$ ). At t0, out of 102 operators enrolled in the study, total anti-SARSCoV-2 antibodies from 54 participants were measured resulting as follows: 49 non-reactive $(90.74 \%)$ and 6 reactive $(11.11 \%)$. At 11 , 78 operators were tested resulting in 12 non-reactive $(15.38 \%)$ and 66 reactive $(84.61 \%)$. At $\mathrm{t} 2$, sera from 101 operators were analyzed: 3 were non-reactive $(2.97 \%)$ and 98 reactive $(97.02 \%)$. At 




B

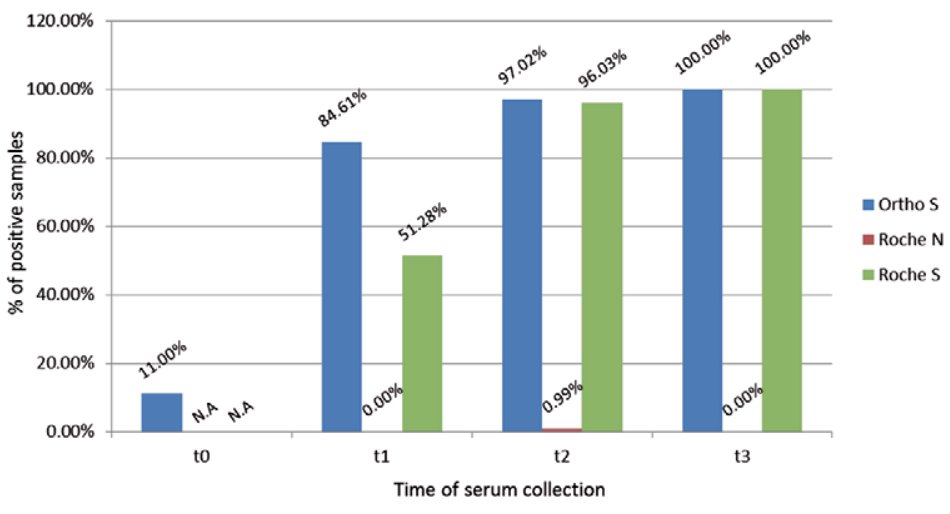

Figure 1. A) Box plot reporting total antibodies anti SARS-CoV-2 distribution (expressed as S/CO) detected at 0-11 days, 12, 21 and 28 days from the first dose of vaccine administration using OrthoClinicalDiagnosticsVITROS ${ }^{\oplus}$ Anti-SARS-CoV-2 Total assay. B) Comparison among percentage of positivity at different times for each of the three methods: OrthoClinicalDiagnosticsVITROS ${ }^{\circledR}$ AntiSARS-CoV-2 Total, Roche Elecsys ${ }^{\oplus}$ Anti-SARS-CoV-2, Roche Elecsys ${ }^{\circledast}$ Anti-SARS-CoV-2 S. (N.A: data not available).

$\mathrm{t} 3$, all 101 operators analyzed were reactive (100\%) including the three operators' samples resulted non-reactive at t2; (Figure 1). Our data correlates with literature which reports that the vaccine shows an efficacy of $52 \%$ between the 1 st and the 2 nd dose (8), calculated on cases of infection occurring in the vaccinated group compared with the placebo group demonstrating that immunity already starts about 12 days after the first dose. This correlates with percentages of positivity to anti-S antibodies already found in our cohort of healthcare professionals few days after the first dose. The positivity to total antibodies starts from $10.90 \%$ found in the collected samples at t 0 , and reaches $84.81 \%$ at $\mathrm{t} 1,96.84 \%$ at $\mathrm{t} 2$ and finally $100 \%$ at $\mathrm{t} 3$. In order to investigate the characteristics of this immune response and specifically trace them back to the vaccine, all sera of $\mathrm{t} 1, \mathrm{t} 2$ and $\mathrm{t} 3$ were analyzed using other two Roche Elecsys ${ }^{\circledR}$ methods, based on detection of two different types of antibodies directed against protein $\mathrm{S}$ or protein N. In our cohort we observed that at $\mathrm{t} 1, \mathrm{t} 2$ and $\mathrm{t} 3$, all sera were negative for anti-N antibodies, except for one that resulted positive, presumably due to a previous asymptomatic SARS-CoV-2 infection (Figure 1). Since it has been reported that in the sera from SARS-CoV-2 patients both anti-N and anti-S antibodies are detected (9), as expected Pfizer/BioNTech BNT162b2 vaccinated subjects specifically develop antibodies against the protein $\mathrm{S}$, encoded by the vaccine mRNA and not against the most abundant nucleocapsid viral protein (10-12). Furthermore, it is interesting to note how the comparison between the two methods directed to anti $\mathrm{S}$ antibodies (Roche $\mathrm{S}$ and Ortho) show a $100 \%$ agreement at $\mathrm{t} 3$, although at $\mathrm{t} 1$ and $\mathrm{t} 2$ there is a discrepancy due to the different sensitivity of the methods (Figure 1B). In fact, as stated by the manufacturer, sensitivity increases with time from diagnosis or from the onset of symptoms and is different for each of the methods used $\left(100 \%\right.$ at $8^{\text {th }}$ day Ortho, $98.8 \%$ at $14^{\text {th }}$ day Roche).

\section{Conclusions}

Administration of Pfizer/BioNTech BNT162b2 vaccine in our cohort showed that the subjects specifically developed antibodies directed to the protein $\mathrm{S}$ encoded by the vaccine mRNA. The presence of neutralizing antibodies occurs already at 12 days from the first dose and the positivity rate increases significantly up to 7 days from the administration of the second dose in which it reaches $100 \%$ with both methods (Roche and Ortho). All vaccinated operators, who had never developed the disease, did not show the presence of anti-N antibodies. In this scenario, the combined use of serological tests directed against different viral proteins is very useful in discriminating the antibody positivity derived from post vaccine immunization or post primary SARS-CoV2 infection. Serological tests used in our study showed to be an excellent tool for monitoring antibodies activity, assess the immunization provided by the vaccine, the immune status of subjects who become infected during vaccination and that of patients with previous COVID-19 infection.

\section{References}

1. Mulligan MJ, Lyke KE, Kitchin N, et al. Phase I/II study of COVID-19 RNA vaccine BNT162b1 in adults. Nature 2020;586:589-93.

2. Sahin U, Muik A, Derhovanessian E, et al. Concurrent human antibody and TH1 type T-cell responses elicited by a COVID19 RNA vaccine. medRxiv 2020/07/20.

3. Walls AC, Park YJ, Tortorici MA, et al. Structure, Function, and Antigenicity of the SARS-CoV-2 Spike Glycoprotein. Cell 2020;183:1735.

4. Hoffmann M, Kleine-Weber H, Schroeder S, et al. SARS-CoV2 Cell Entry Depends on ACE2 and TMPRSS2 and Is Blocked by a Clinically Proven Protease Inhibitor. Cell 2020;181:271-80.

5. Lan J, Ge J, Yu J, et al. Structure of the SARS-CoV-2 spike receptor-binding domain bound to the ACE2 receptor. Nature 2020;581:215-20.

6. Lu R, Zhao X, Li J, et al. Genomic characterization and epidemiology of 2019 novel coronavirus: implications for virus origins and receptor binding. Lancet 2020;395:565-74.

7. Wrapp D, Wang N, Corbett KS, et al. Cryo-EM Structure of the 2019-nCoV Spike in the Prefusion Conformation. bioRxiv. $2020 \mathrm{Feb} 15$.

8. Mahase E. Covid-19: Pfizer vaccine efficacy was 52\% after first dose and 95\% after second dose, paper shows. BMJ 2020;371:m4826.

9. Liu W, Liu L, Kou G, et al. Evaluation of Nucleocapsid and 
Spike Protein-Based Enzyme-Linked Immunosorbent Assays for Detecting Antibodies against SARS-CoV-2. J Clin Microbiol 2020;58.

10. To KK, Tsang OT, Leung WS, et al. Temporal profiles of viral load in posterior oropharyngeal saliva samples and serum antibody responses during infection by SARS-CoV-2: an observational cohort study. Lancet Infect Dis 2020;20:565-74.
11. Liu W, Liu L, Kou G, et al. Evaluation of nucleocapsid and spike protein-based enzyme-linked immunosorbent assays for detecting antibodies against SARS-CoV-2. J Clin Microbiol 2020;58:e0461-20.

12. Long QX, Liu BZ, Deng HJ, et al. Antibody responses to SARS-CoV-2 in patients with COVID-19. Nat Med 2020;26: 845-8. 